\title{
Lab Extreme: experiência ao reestruturar o laboratório de informática de uma escola da rede pública
}

\author{
Kayk Costa de Almeida ${ }^{1}$, Iara Garcia Pinto ${ }^{1}$, Victor Matheus Souza dos Santos ${ }^{1}$, \\ Lucas Moura Oliveira ${ }^{1}$, Decíola Fernandes de Sousa ${ }^{2}$ \\ Instituto Ciberespacial (ICIBE) - Universidade Federal Rural da Amazônia (UFRA) \\ 66.077-830 - Belém - PA - Brasil \\ \{kaykalmeida10, iaragarcia06, victormatheus84, \\ oliveiralucas0906\} @gmail.com, deciola.sousa@ufra.edu.br
}

\begin{abstract}
The Information and Communication Technologies are present in every sphere of society. Knowing of this importance, a project sought to improve the conditions of computer education in a State school through the restructuring of its computer lab. Activities such as workspace cleaning and organization, equipment maintenance, operating system configuration and updates and network structure organization were the main tasks performed by the members of the Lab Extreme Project - an undergraduate computing course student initiative.
\end{abstract}

Resumo. As Tecnologias da Informação e do Conhecimento estão presentes em todas as esferas da sociedade. Sabendo dessa importância, foi desenvolvido um projeto que visava melhorar as condições do ensino da computação em uma escola estadual por meio da reestruturação do laboratório de informática. Atividades como limpeza e organização do espaço, manutenção de equipamentos, atualização e configuração dos sistemas operacionais e ordenação da estrutura de rede foram as principais tarefas realizadas pelos membros do projeto Lab Extreme - iniciativa de discentes do curso de Licenciatura em Computação.

\section{Introdução}

É perceptível a crescente presença das tecnologias em várias esferas da sociedade. Por ser considerada propulsora de mudanças, a Tecnologia da Informação e do Conhecimento (TIC) está assumindo cada dia mais espaço em nossas vidas. Seja em tarefas complexas ou atividades simples, essa influência está moldando o comportamento humano e suas necessidades. De acordo com Cunha e Gurgel (2016) a TIC está:

[...]trazendo novas possibilidades informacionais, comunicacionais e cognitivas. A incorporação destas no cotidiano social, exige das pessoas conhecimentos e habilidades acerca de sua utilização, tendo em vista que, atividades rotineiras como uma simples consulta bancária, tornamse desafiadoras quando o indivíduo não está familiarizado com as tecnologias. Dessa forma, nos dias atuais, é imprescindível que além do ler e escrever, as pessoas possuam noções básicas de informática e acesso às TICs. [CUNHA e GURGEL, 2016, p. 418].

\footnotetext{
${ }^{1}$ Aluno do Curso de Licenciatura em Computação da Universidade Federal Rural da Amazônia.

2 Professora do Curso de Licenciatura em Computação da Universidade Federal Rural da Amazônia.
} 
Existem várias maneiras de adquirir os conhecimentos e habilidades exigidas pela TIC. Meios midiáticos, como a televisão e o jornal, plataformas digitais na Internet ou até mesmo o convívio em sociedade permite que os indivíduos consigam se relacionar e assimilar as tecnologias que estão em sua volta. Para Lima et al (2007, p. 1) "a tecnologia na atualidade está presente em todas as instâncias da sociedade e a educação, sendo a principal instituição social responsável pela formação do cidadão, tem o papel de incluílo na sociedade".

O crescente ritmo na qual as tecnologias evoluem implica na necessidade do homem de se adaptar. Neste cenário o ensino da informática assume um papel significativo, cabendo à escola dar os primeiros passos para que isso ocorra. Canez e Severo (2016, p. 476) comentam que "a escola tem a função de formar cidadãos, dar aos alunos os ensinamentos da qual necessitam para viver e trabalhar neste mundo de evolução, bem como orientá-los para a vida". A escola torna-se, mais uma vez, o alicerce para a o convívio em sociedade, talhando as gerações futuras para o mundo cada vez mais competitivo e tecnológico.

Todavia, os obstáculos que permeiam esse ensino desafiam a plenitude da educação na TIC. Por terem dificuldades, alunos não compreendem os mecanismos e ferramentas tecnológicas que estão à sua disposição, cometendo falhas ou equívocos. Canez e Severo (2016) exemplificam:

Ao concluírem o ensino fundamental muitos estudantes têm dificuldades para realizar pesquisas e trabalhos escolares. Diversos problemas podem ser observados em muitos trabalhos escolares, pois é um "copia e cola" desenfreado, sem formatação correta, com assuntos que acabam fugindo da proposta apresentada pelo professor. [CANEZ e SEVERO, 2016, p. 477].

Essas dificuldades são ainda mais evidentes em escolas públicas. Embora haja uma iniciativa governamental de intensificar o ensino da informática, por meio de programas como o ProInfo (Programa Nacional de Tecnologia Educacional), que visa promover o uso pedagógico da informática na rede pública de educação básica, proporcionando computadores, recursos digitais e conteúdos educacionais. O que se vê na prática é que existem barreiras a serem ultrapassadas. Um exemplo é a falta, no âmbito escolar, do profissional de Licenciatura em Computação que exerça efetivamente a gestão do laboratório de informática .

Muitas das escolas públicas enfrentam problemas estruturais severos, principalmente nas salas de informática. Um dos motivos é a falta de um suporte técnico ativo, provocando certos problemas, tais quais: laboratórios de informática desorganizados ou sucateados; computadores com sistemas, programas e recursos desatualizados ou desconfigurados; estrutura elétrica e lógica comprometidas ou ineficientes e outros. Ao se observar esses desafios, torna-se fundamental procurar soluções que minimizem esses problemas nos espaços da educação básica.

O objetivo do artigo é relatar a experiência do projeto que foi desenvolvido por alunos do curso de Licenciatura em Computação da Universidade Federal Rural da Amazônia (UFRA) em uma escola pública de Belém-PA, que visou a reestruturação do laboratório de informática. Por meio de atividades como limpeza e organização do espaço, manutenção dos equipamentos, atualização e configuração dos sistemas operacionais, ordenação da estrutura de rede e outras, foi possível envolver acadêmicos e 
VI Congresso Brasileiro de Informática na Educação (CBIE 2017)

Anais dos Workshops do VI Congresso Brasileiro de Informática na Educação (WCBIE 2017)

instituição de ensino, promovendo a aprendizagem das coisas e estreitando a distância da teoria com a prática. $\mathrm{O}$ artigo apresenta na seção 2 a contextualização do projeto, na seção 3 as atividades do projeto, os resultados e discussão na seção 4 e as considerações finais na seção 5 .

\section{Contextualizando o projeto}

O uso das tecnologias nas instituições educacionais tem como objetivo proporcionar uma qualidade para os métodos de ensino e aprendizagem vigentes atualmente. Utilizando os laboratórios de informática, onde alunos poderão ter acesso às tecnologias e a métodos não tradicionais de ensino, a escola transmite conhecimento e universaliza o uso da TIC ao mesmo tempo em que se agrega de diversas ferramentas de ensino para construir o seu ambiente educacional. Segundo Tajra (2000):

A importância da utilização da tecnologia computacional na área educacional é indiscutível e necessária, seja no sentido pedagógico, seja no sentido social. Não cabe mais à escola preparar o aluno apenas nas habilidades de linguística e lógico-matemática, apresentar o conhecimento dividido em partes, fazer do professor o grande detentor de todo o conhecimento e valorizar apenas a memorização. Hoje, com o novo conceito de inteligência, em que podemos desenvolver as pessoas em suas diversas habilidades, o computador aparece num momento bastante oportuno, inclusive para facilitar o desenvolvimento dessas habilidades - lógico-matemática, linguística, interpessoal, intrapessoal, espacial, musical, corpo-cinestésica, naturista e pictórica. [TAJRA, 2000, p. 32].

Nesse contexto, os laboratórios de informática das escolas adquirem vital importância no estímulo das diversas habilidades do aluno. Mantê-los conservados e operacionais é fundamental, porém, com o passar do tempo, esses ambientes, recursos e ferramentas digitais utilizados vão se deteriorando. O monitoramento e manutenção fazem-se necessários à medida que os problemas estruturais aparecem. No artigo de Costa et al (2009), que aborda oficinas de tecnologia promovidas para os funcionários e professores do ensino básico, é proposta uma medida de contorno para solucionar o problema de monitoramento. É colocado "algum professor que tenha pouca carga-horária em sala de aula para assumir a responsabilidade do laboratório de informática, quando a atitude certa, seria um professor licenciado em informática ou em outro curso de tecnologia" [COSTA et al, 2009, p. 6].

Os recursos humanos e a infraestrutura dos laboratórios de informática necessitam de mais investimentos. Pensando nisso, foi concebido o projeto Lab Extreme. Uma iniciativa acadêmica realizada por graduandos de Licenciatura em Computação, que visou melhorar as condições de ensino da informática em uma escola da rede pública, utilizando os recursos disponíveis na instituição. Os membros do projeto planejaram e desenvolveram atividades que otimizaram a infraestrutura da escola, e consequentemente, impactaram nas práticas de ensino da computação.

O projeto foi realizado no primeiro trimestre de 2017 em uma escola estadual de ensino fundamental e médio da cidade de Belém, pelo período de 8 (oito) semanas, onde foi contemplado por atividades de manutenção e suporte técnico. O principal objetivo foi promover uma reestruturação do laboratório de informática, fazendo com que todos os equipamentos e recursos sejam reutilizados, com o intuito de melhorar a experiência de 
VI Congresso Brasileiro de Informática na Educação (CBIE 2017)

Anais dos Workshops do VI Congresso Brasileiro de Informática na Educação (WCBIE 2017)

ensino e aprendizagem. Na prática, o projeto Lab Extreme foi uma tentativa de proporcionar mais uma chance para uma educação de computação com qualidade.

\section{Atividades do Projeto}

A escola estadual onde ocorreu o projeto já era conhecida pelos membros do Lab Extreme, pois três de seus quatro participantes eram bolsistas do Programa Institucional de Bolsa de Iniciação à Docência (PIBID) e atuavam no local. Embora o projeto não tivesse nenhum vínculo direto com o programa, a boa relação entre direção da escola e bolsistas facilitou a adesão ao projeto.

Antes de iniciar o planejamento, dois membros do Lab Extreme conversaram com a direção e o professor responsável pelo laboratório de informática. A situação do espaço, questões burocráticas e logísticas foram a principal pauta da reunião. Posteriormente, foi revelado que a escola possuía um termo permitindo que os equipamentos e computadores disponíveis no laboratório poderiam ser examinados e consertados, caso necessário.

\subsection{Planejamento e recursos}

O planejamento se iniciou imediatamente após a liberação por parte da escola, e se estendeu por duas semanas. Uma visita na primeira semana, de caráter técnico, foi realizada no laboratório a fim de verificar as condições do espaço em questão. Foi constatado que havia uma diversificação considerável de computadores e periféricos. Uma rápida contagem sugeria que havia aproximadamente: (i) 25 (vinte e cinco) gabinetes de diversos modelos, com seus respectivos periféricos; (ii) 15 (quinze) equipamentos para corrigir a tensão elétrica, distribuídos entre nobreaks, estabilizadores e filtros de linha; (iii) 30 (trinta) monitores de padrões e tamanhos diferentes; (iv) 1 (uma) caixa de som amplificada; (v) 3 (três) projetores digitais e (vi) 1 (uma) impressora. Haviam outros equipamentos complementares, como fones de ouvido, microfones, notebooks, periféricos quaisquer e alguns gabinetes avariados.

Para facilitar a comunicação e gestão estratégica entre os membros da equipe, foram utilizados serviços digitais com o intuito de potencializar a execução e o gerenciamento do projeto. Serviços gratuitos como: Onedrive (2017), Microsoft Office Online (2017), Skype (2017), Trello (2017) e WhatsApp Messenger (2017) foram de vital importância para o sucesso do projeto.

O serviço de compartilhamento de arquivos na nuvem da Microsoft, o Onedrive (2017), foi utilizado para armazenar todos os arquivos referentes ao projeto, como: documentos, planilhas, imagens, vídeos, áudios e arquivos afins. O mesmo, gera uma possibilidade de compartilhamento avançado usando apenas o $e$-mail, e a utilização do pacote Microsoft Office Online (2017) - que contém Word, Excel e outros softwares sem nenhum custo adicional e resultou numa maximização na troca e edição de arquivos. Outro serviço da Microsoft utilizado foi o Skype (2017) que é um programa de comunicação pela internet via videoconferência. O software foi utilizado para todas as reuniões online desde o planejamento até a finalização do projeto. Utilizando uma ferramenta dentro do sistema, foi possível também utilizar a função de gravar todas as reuniões.

O Trello (2017) é uma ferramenta online para gerenciamento de projetos que utiliza a metodologia Kanban (que mostra o progresso de tarefas de forma visual). $\mathrm{O}$ funcionamento do Trello (2017), baseado nesta metodologia, é modelado basicamente em 
VI Congresso Brasileiro de Informática na Educação (CBIE 2017)

Anais dos Workshops do VI Congresso Brasileiro de Informática na Educação (WCBIE 2017)

forma de cards e colunas, onde estão contidas as informações e ferramentas de gerenciamento de tarefas. Andrade at el (2016) mostra como foi utilizada a aplicação do Trello (2017) em seu respectivo projeto, que convenientemente foi adotado pelos membros do Lab Extreme. Nisso, o autor conta um pouco da experiência com a ferramenta:

Este gerenciador de atividades [...] permitiu que cada time pudesse controlar de forma eficaz as tarefas, estabelecendo uma organização, ao mesmo tempo em que era possível classificar as atividades a serem realizadas em "Tarefas não iniciadas", "Em progresso" e "Concluídas". [ANDRADE at el, 2016, p. 256].

Outro aplicativo utilizado foi o WhatsApp Messenger (2017) que é uma aplicação multiplataforma e de fácil aquisição. Por se tratar de um mensageiro instantâneo, foi o comunicador informal mais utilizado durante o projeto. Um grupo foi criado contendo somente os envolvidos no projeto, e nele houveram trocas de ideias e informações urgentes que eram repassadas através dele.

Obras sobre gerenciamento de projetos, como os de Calôba e Klaes (2016) e de sistemas Linux, como Negus (2014), serviram de fonte de consulta e orientações no período de planejamento.

O cronograma do projeto, Tabela 1, foi realizado em conjunto, fruto de várias reuniões da equipe.

Tabela 1. Cronograma do Projeto

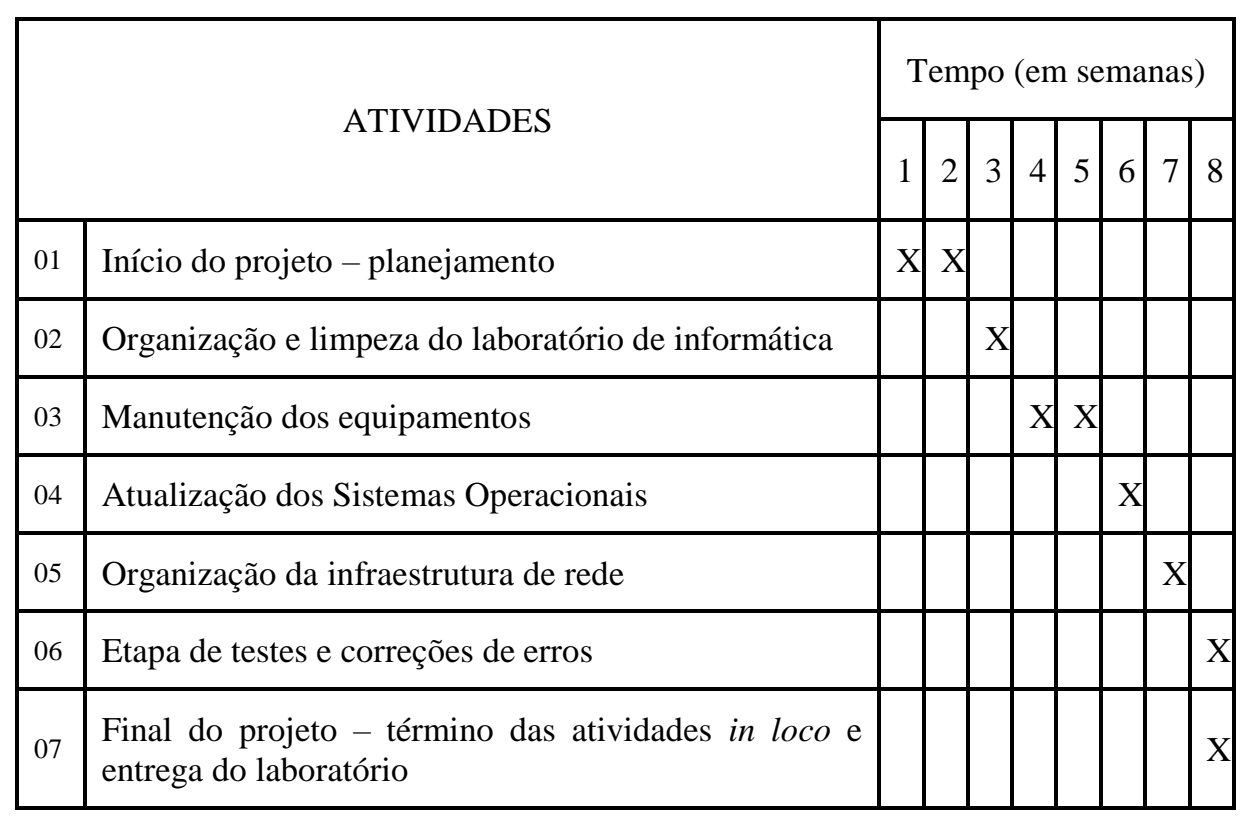

Levando em consideração que a escola entraria em recesso letivo durante todo o mês de fevereiro, e que no início de março ocorreriam o período de matrículas escolares, o cronograma do projeto (Tabela 1) foi pensado no intervalo de 8 (oito) semanas, das quais 2 (duas) seriam de planejamento e 6 (seis) de atividades in loco. 
VI Congresso Brasileiro de Informática na Educação (CBIE 2017)

Anais dos Workshops do VI Congresso Brasileiro de Informática na Educação (WCBIE 2017)

\subsection{Atividades in loco}

As atividades de manutenção e reestruturação do laboratório ocorreram da terceira à oitava semana do projeto. Na semana 3 (três), os integrantes da equipe se ocuparam com limpeza do local. O ambiente estava demasiadamente sujo, servindo como depósito de livros didáticos, que posteriormente seriam entregues aos alunos. A direção da escola disponibilizou material de limpeza e apoio da equipe responsável pela limpeza da escola.

Na semana 4 (quatro) iniciou-se a manutenção dos computadores e equipamentos. Foi verificada a integridade dos gabinetes, monitores, teclados, mouses, cabos de energia e vídeo, nobreaks, estabilizadores, pontos elétricos e lógicos de rede, etc. Os computadores estavam distribuídos em mesas de formato "L", com seus respectivos periféricos, que haviam sido organizados durante a semana anterior. Os gabinetes estavam sujos, com peças mal encaixadas ou danificadas. A equipe do Lab Extreme dispunha de todas as ferramentas necessárias para a manutenção, como chaves de fenda, parafusos, testadores de tensão, cabos Sata, pasta térmica, álcool isopropílico, flanelas, pincéis, luvas, baterias, etc.

Uma força tarefa foi realizada para demandar a limpeza de todos os computadores. Essa colaboração resultou em 20 (vinte) gabinetes completos e limpos. Os restantes dos gabinetes serviram para repor peças, seus componentes danificados serviriam para o auxílio de futuras aulas de manutenção. Antes do projeto, haviam apenas 7 (sete) computadores operacionais, porém após a limpeza e manutenção, os 20 (vinte) dos 25 (vinte e cinco) computadores estavam em pleno funcionando.

O principal objetivo da semana 6 (seis) era verificar a integridade e situação dos sistemas operacionais (SO). Por se tratar de computadores diferentes, seus SOs estavam em versões e distribuições também diferentes. Ao todo, foram encontrados 3 (três) SOs: (i) Linux Educacional 4 (2017), presentes em 7 (sete) computadores com $512 \mathrm{MB}$ de memória RAM; (ii) Linux Educacional 5 (2017), presentes em 7 (sete) computadores com 1 GB de memória RAM; (iii) BotoSet Linux (2017), presente em 6 (seis) computadores com $1 \mathrm{~GB}$ de memória $R A M$.

Os computadores que não apresentavam problemas no sistema operacional tiveram seus sistemas mantidos, sendo feita apenas uma atualização via terminal de comando. Para os computadores que apresentaram o sistema corrompido, foi realizada a instalação manual do Linux Educacional 4 (2017) e Linux Educacional 5 (2017), por meio de CDs disponíveis na própria escola. Houve a intenção de instalar outras distribuições Linux como Xubuntu (2017) e Lubuntu (2017), da Canonical. Entretanto, por se tratar de um ambiente educacional, foi preservado os sistemas originais.

A semana 7 (sete) foi reservada para a organização da estrutura de rede do laboratório e informática. Conectores de rede $R J 45$ foram substituídos e cabos de rede foram rearranjados. Testes de conexões foram realizadas nos computadores que não possuíam acesso à internet.

E por fim, a semana 8 (oito) se iniciou o período de testes e correções de erros. Após verificar a conexão da rede nos computadores, as principais aplicações (editores, navegadores e softwares educacionais) e usuários do sistema operacional, foi entregue o laboratório à direção da escola. 
VI Congresso Brasileiro de Informática na Educação (CBIE 2017)

Anais dos Workshops do VI Congresso Brasileiro de Informática na Educação (WCBIE 2017)

\section{Resultados e Discussões}

A possibilidade de utilizar o laboratório de informática em condições adequadas com recursos e ferramentas operantes, sempre foi a meta de todos os envolvidos no projeto. Proporcionar aos professores da instituição subsídios para que seja possível desenvolver atividades complementares com seus alunos, aumentando a interdisciplinaridade e propiciando mais acesso à informação e tecnologia, era uma consequência prevista do trabalho realizado. Pensando nessa consequência, foi planeado o treinamento futuro dos professores, no intuito de utilizarem efetivamente o laboratório. O computador é uma interessante ferramenta de aprendizagem que deve ser incorporada na didática dos professores e introduzir conceitos e fundamentos da computação ajuda a promover a aprendizagem das coisas (bastante comum no ambiente ciberespacial). $\mathrm{O}$ aluno sente-se mais instigado e motivado a aprender quando o professor utiliza a TIC como uma ferramenta educacional.

Os bolsistas pertencentes ao Programa Institucional de Bolsa de Iniciação à Docência (PIBID), que atuam na escola, também foram impactados com o projeto. Eles tiveram oportunidades de oferecer mais opções de cursos e oficinas relacionados a computação, utilizando os computadores que a priori não funcionavam. Ao término do projeto, do total de 25 (vinte e cinco) computadores da escola, 20 (vinte) tornaram-se operacionais. A figura 1 apresenta a situação dos computadores da escola ao término do projeto.

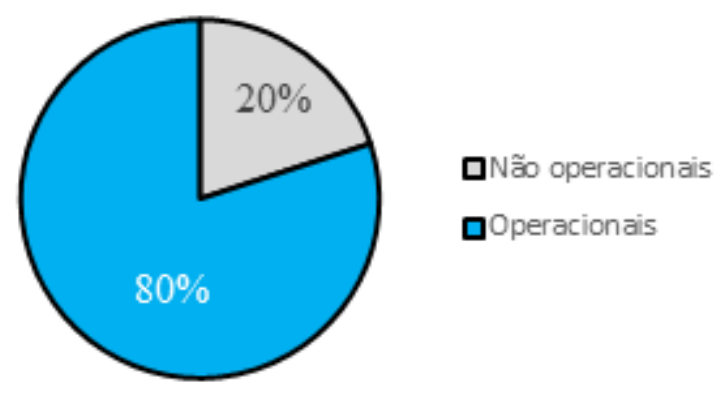

Figura 1. Situação dos computadores após o projeto

A distribuição dos sistemas operacionais também é um fator importante a se destacar, conforme Figura 2.

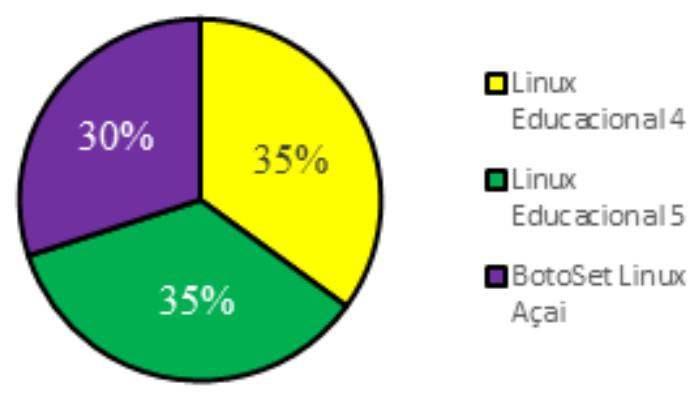

Figura 2. Distribuição dos Sistemas Operacionais após o projeto 
VI Congresso Brasileiro de Informática na Educação (CBIE 2017)

Anais dos Workshops do VI Congresso Brasileiro de Informática na Educação (WCBIE 2017)

Ao término do projeto, $35 \%$ dos computadores operacionais continham o Linux Educacional 4 (2017), 35\% tinham o BotoSet Linux Açaí (2017) e o restante dos 30\% eram compostos com Linux Educacional 5 (2017). Embora as máquinas apresentassem limitações técnicas, os sistemas demonstraram relativa estabilidade. Utilização de softwares de edição de texto, planilhas e Internet responderam bem aos testes realizados.

E por fim, por se tratar de uma iniciativa de acadêmicos de Licenciatura em Computação da Universidade Federal Rural da Amazônia (UFRA), os envolvidos no projeto puderam experimentar e se aperfeiçoar profissionalmente e intelectualmente. Envolvendo atividades teóricas e práticas, o projeto Lab Extreme pode ser implementado por qualquer graduando da área de tecnologia. Os conhecimentos técnicos necessários para realizar as atividades são simples e caso os universitários não a possuam, um orientador ou profissional conseguirá guiá-los com facilidade. A maioria dos problemas encontrados durante a execução do projeto tiveram considerável esforço pessoal. A mais evidente foi a questão do tempo. Pelo fato da escola permanecer em recesso do ano letivo por aproximadamente um mês e meio, todas as atividades planejadas precisaram ser encaixadas nesse período. A equipe era composta por quatro graduandos, que revezavam durante os turnos da manhã e tarde, com carga horária de 3 (três) a 4 (quatro) horas diárias. O gerenciamento de tempo foi fundamental para alcançar o prazo estipulado.

\section{Considerações finais}

O artigo apresentou uma experiência criada e desenvolvida para reestruturar um laboratório de informática de uma escola pública por discentes do curso de Licenciatura em Computação, estreitando a relação dos acadêmicos com a escola. Esses espaços são de grande importância, pois a TIC está exigindo cada vez mais habilidades e a sociedade precisa estar preparada para este avanço tecnológico. O laboratório de informática é uma das inúmeras formas de proporcionar a inclusão e o acesso à informação, e neste contexto, as escolas precisam ter estes espaços para desenvolver intelectos e introduzir novos conhecimentos na comunidade escolar.

O projeto Lab Extreme foi uma iniciativa que visou melhorar as condições de ensino da computação. Tarefas como limpeza, manutenção e instalação de computadores foram umas das atividades realizadas a fim de preparar o espaço para atividades futuras. Ao final do projeto, o laboratório voltou a fazer parte da rotina da escola. Cursos como digitação, pacote office (LibreOffice), noções de Internet, e-mail e manutenção de computadores puderam ser realizados pelos membros do PIBID e também da comunidade escolar.

Outro ponto importante a ser destacado é a intenção do projeto de incentivar os professores a utilizarem o laboratório em suas aulas. Uma das atividades futuras é a proposta de um pequeno treinamento das ferramentas educacionais disponíveis nos computadores aos professores, para que eles possam entender como utilizá-las. Com o apoio da direção da escola, esse treinamento poderá ser apresentado pelos membros do Lab Extreme e do PIBID, pois é fundamental esse trabalho contínuo, com novos projetos e ideias que coincidam com a proposta de aprimorar a educação. Por fim, vale ressaltar que o sucesso do projeto demonstra que qualquer um com motivações e esforços certos podem fazer a diferença. 
VI Congresso Brasileiro de Informática na Educação (CBIE 2017)

Anais dos Workshops do VI Congresso Brasileiro de Informática na Educação (WCBIE 2017)

\section{Referências}

Andrade, B., Brito, M. e Lima, C. (2016) "Metodologia Ágil Scrum em uma Disciplina de Engenharia de Software", In $5^{\circ}$ Congresso Brasileiro de Informática na Educação (CBIE 2016), 22 ${ }^{\circ}$ Workshop de Informática na Escola (WIE 2016), p. 251 - 260.

Botoset Linux (2017) https://launchpad.net/botoset, 28 de maio de 2017.

Calôba, G. e Klaes, M. (2016) "Gerenciamento de Projetos com PDCA", 1. ed. Rio de Janeiro: Alta Books.

Canez, A. e Severo, C. (2016) "Implicações do software livre no ensino e aprendizagem: um estudo de caso no ensino médio politécnico", In $5^{\circ}$ Congresso Brasileiro de Informática na Educação (CBIE 2016), $22^{\circ}$ Workshop de Informática na Escola (WIE 2016), p. $476-484$.

Costa, R., Barros, V., Pinto, J., Silvestre, J., Neiva, L. e Junior, A. (2009) "Internet e Laboratório de Informática: Dois Importantes Recursos Metodológicos para Surpreender os Estudantes e Beneficiar a Interdisciplinaridade", In $20^{\circ}$ Simpósio Brasileiro de Informática na Educação (SBIE 2009), 8p.

Cunha, R. e Gurgel, R. (2016) "Práticas de Inclusão Digital na Educação de Jovens e Adultos: minicurso de Introdução à Informática", In $5^{\circ}$ Congresso Brasileiro de Informática na Educação (CBIE 2016), $22^{\circ}$ Workshop de Informática na Escola (WIE 2016), p. $417-426$.

Lima, M., Silva, N., Araújo, R. e Abranches, S. (2007) “O impacto do uso das tecnologias no aprendizado dos alunos do Ensino Fundamental 1", Trabalho de Conclusão de Curso (Graduação em Pedagogia), Universidade Federal de Pernambuco.

Linux Educacional 4 (2017) https://linuxeducacional.c3sl.ufpr.br/LE4/, 28 de maio de 2017.

Linux Educacional 5 (2017) https://linuxeducacional.c3sl.ufpr.br/LE5/, 28 de maio de 2017.

Lubuntu (2017) http://lubuntu.net/, 28 de maio de 2017.

Microsoft Office Online (2017) https://products.office.com/pt-br/officeonline/documents-spreadsheets-presentations-office-online, 28 de maio de 2017.

Negus, C. (2014) "Linux a Bíblia: O Mais Abrangente e Definitivo Guia Sobre Linux", 1. ed. Rio de Janeiro: Alta Books.

Onedrive (2017) https://onedrive.live.com/, 28 de maio de 2017.

Tajra, S. (2000) "Informática na educação: novas ferramentas pedagógicas para o professor da atualidade", 2. ed. São Paulo: Érica.

Skype (2017) https://www.skype.com/pt-br/, 28 de maio de 2017.

Trello (2017) https://trello.com/, 28 de maio de 2017.

WhatsApp (2017) https://www.whatsapp.com/, 28 de maio de 2017.

Xubuntu (2017) https://xubuntu.org/, 28 de maio de 2017. 